\title{
Andrew Clapham, Mary Robinson (eds) and Claire Mahon, Scott Jerbi (co-eds.): Realizing the Right to Health
}

\author{
Swiss Human Rights Book, Vol.3, edited by the Chair of Political Philosophy \\ of the University of Zurich, Switzerland, rüffer \& rub, 2009, ISBN: 978-3-907625-45-3
}

\author{
Jana Arloth
}

Received: 8 September 2009 /Accepted: 8 September 2009/Published online: 17 March 2010

(C) Springer-Verlag 2010

Over the last decade, the right to health has gained increasing prominence at the international level, and the third volume of the Swiss Human Rights Book series adds to the rising demand to view health care through a human rights lens. Discussing the scope of the right to health enshrined in the 1966 International Covenant on Economic, Social and Cultural Rights, the collection of essays edited by Mary Robinson, President of 'Realizing Rights', and Andrew Clapham, Director of the Geneva Academy of International Humanitarian Law and Human Rights, contributes to the perception of health as a fundamental human right and the understanding of that right's essence. In addition, it imparts a vivid understanding of measures that need to be taken in order to bring the right to health closer to reality.

The attraction and strength of the publication is that both health and human rights advocates share their thoughts about how the underlying principles of human rights and the right to health can help to influence policy making and action regarding health interventions at every level. The book argues that a twenty-first century approach is needed which widens the spectrum of actors traditionally occupied with ensuring the right to health for all. The essays serve the purpose of contributing to that goal by discussing what it means to take a right-based approach in many different health-related areas.

In other words, the right to the highest attainable standard of health, which covers the traditional spheres of medical care as well as public health, is explored from a

\footnotetext{
J. Arloth ( $\triangle)$

Research Association Public Health Saxony

and Saxony-Anhalt e. V., Faculty of Medicine, TU Dresden, Fiedlerstr. 33,

01307 Dresden, Germany

e-mail: jana_arloth@web.de
}

variety of geographic and thematic positions. Fifty-nine leading international health care practitioners, health officials and human rights and gender experts from different regional specifications and various backgrounds, e.g. law, history, development, economics, education, anthropology and political science, offer a comprehensive picture of this challenging issue employing evidence from various sources to make their case with clarity.

In the form of powerful case studies, best practice examples and theoretical texts, the ten chapters, which comprise two to five essays each, take the reader on a journey through an array of core topics, namely, health from a human rights perspective, women's health, the right to health in emergencies, people and groups at risk, key health challenges, multilateral institutions and responses, the role of health care practitioners, the strengthening of health care systems, the role of governments and civil society and strategies for realizing the right to health.

Each essay is supplemented by useful footnotes, which point to some supplementary sources for further reading. An index at the end of the publication, which would assist the reader in tracing subjects in the text, is, however, missing.

Due to the variety of disciplines and perspectives, the book comprises different writing styles. Yet, this does not have any negative effect; on the contrary, it underlines the diversity and complexity of the issue.

With respect to the readership, the book will stand as a valuable resource for the public health and human rights audience. Furthermore, the book is a timely contribution for everyone with a general interest in an up-to-date account of why it is so essential that health systems in general and their national health sector and health workforce strategies in particular adopt an approach which is defined by human rights principles. 